\title{
Simulação da quantidade máxima de domicílios permitida por quadras em Belo Horizonte*
}

\author{
Glauco Umbelino** \\ Clodoveu Davis Jr. ${ }^{\star \star *}$
}

\begin{abstract}
O artigo propõe uma metodologia de simulação da quantidade máxima de domicílios comportada por cada quadra do município de Belo Horizonte. Os parâmetros utilizados na simulação foram extraídos das informações cadastrais da Prefeitura, associadas com os resultados dos Censos 2000 e 2010. A simulação é desenvolvida a partir de uma base georreferenciada das quadras do município, construída a partir do mapeamento dasimétrico da distribuição domiciliar na capital mineira em 2011. Em um segundo momento, é realizada a simulação do limite máximo de novos domicílios permitidos pelas leis municipais, caso todos os lotes vagos sejam ocupados em sua capacidade máxima e caso todas as edificações com potencial de demolição cedam lugar a novos edifícios residenciais também construídos em sua capacidade domiciliar máxima. Os resultados mostram qual seria o máximo de domicílios que poderia vir a se instalar em Belo Horizonte no futuro. Estas informações servem como insumo para os dados de projeções demográficas de pequenas áreas, ao apontar onde a expansão e o adensamento domiciliar podem ocorrer, bem como o limite máximo suportado em cada quadra. De forma complementar, são indicados caminhos para discutir os limites potenciais da ocupação urbana de Belo Horizonte, as áreas preferenciais de adensamento e suas implicações para o planejamento.
\end{abstract}

Palavras-chave: Simulação domiciliar. Geotecnologias. Mapeamento dasimétrico. Expansão urbana.

\footnotetext{
* Os autores agradecem as significativas contribuições do prof. Alisson Barbieri (Cedeplar - UFMG), que orientou a tese que serviu de insumo para este artigo.

${ }^{* *}$ Faculdade Interdisciplinar em Humanidades (FIH), Universidade Federal dos Vales do Jequitinhonha e Mucuri (UFVJM), Diamantina-MG, Brasil (geoglauco@gmail.com).

*** Departamento de Ciência da Computação, Universidade Federal de Minas Gerais (UFMG), Belo Horizonte-MG, Brasil (clodoveu@dcc.ufmg.br).
} 


\section{Introdução}

Um dos grandes desafios dos gestores municipais de países em desenvolvimento é como associar um crescimento urbano que tende a dobrar até 2025 (BREMNER et al., 2010; UNFPA, 2011) a um processo de desenvolvimento urbano inclusivo e sustentável que proporcione a geração de riqueza, a qualidade de vida e a qualidade ambiental para habitantes do presente e do futuro (MARTINE, 2007; BREMNER et al., 2010). A expansão urbana (horizontal) das cidades passa cada vez mais a ser acompanhada do adensamento (expansão vertical) na maioria dos aglomerados urbanos, o que agrava seus problemas de planejamento à medida que a população aumenta (LEMOS et al., 2004; PDDI, 2011; UNFPA, 2011).

Além das questões sobre o desenvolvimento sustentável e inclusivo, a tendência de concentração urbana e os efeitos decorrentes deste processo constituem um grande desafio para o planejamento territorial em termos da ordenação do adensamento (BREMNER et al., 2010; UNFPA, 2011). Tal ordenação tende a evitar ocupações irregulares, bem como prover a população com serviços públicos, infraestrutura urbana e qualidade ambiental adequada nos espaços urbanos.

Equilibrar as demandas por um desenvolvimento urbano inclusivo de forma a contemplar questões físico-territoriais, econômicas, sociais, políticas, ambientais e de gestão tem sido o maior desafio da administração municipal em grandes centros urbanos. Diante desse quadro, a administração pública municipal demanda competência e efetividade dos seus gestores, que devem agir por meio de instrumentos técnicos, modernos e práticos de planejamento e gestão, tais como os advindos das geotecnologias (TORRES, 2006; REZENDE; ULTRAMARI, 2007; UNFPA, 2011).

Essa demanda por qualificação do processo de planejamento encontra um grande desafio nos números: o Censo Demográfico de 2010 mostrou um contingente de 190.755 .799 habitantes vivendo em 67.569.688 domicílios. Calculou-se que cerca de $84 \%$ dessa população está localizada em áreas urbanas, que ocupam aproximadamente 101.503 km², correspondendo a 1,2\% do território nacional (IBGE, 2011). No caso de Belo Horizonte, dos $332,3 \mathrm{~km}^{2}$ do município, foi mensurado que $294,7 \mathrm{~km}^{2}$ estão ocupados pela mancha urbana ${ }^{1}$ e vários locais se encontram com a ocupação futura aprovada, sendo o mais expressivo o Plano Urbano Ambiental da Região do Isidoro, que contempla a expansão urbana de uma área aproximada de $5 \mathrm{~km}^{2}$ (BELO HORIZONTE, 2010).

Nesse contexto, o presente trabalho propõe uma metodologia de simulação por quadra ${ }^{2}$ da capacidade máxima de domicílios permitida em Belo Horizonte, a partir da análise da legislação urbanística e ambiental municipal (Leis n. 7.165/96, 7.166/96 e 9.959/10). Os parâmetros utilizados foram extraídos das informações cadastrais da Prefeitura de Belo

\footnotetext{
${ }_{1}^{1} 0$ conceito de mancha urbana é amplo e complexo em sua definição, mas para fins práticos e metodológicos considerou-se mancha urbana, neste trabalho, a área do município que possui algum elemento de infraestrutura urbana, tais como edificações, equipamentos públicos, ruas e praças.

${ }^{2}$ A quadra ou quarteirão é a unidade de análise formada por um polígono circundado pela malha viária, que comporta todos os lotes e espaços públicos do município.
} 
Horizonte (PBH), associadas aos dados do Universo dos Censos Demográficos de 2000 e 2010. A simulação foi desenvolvida utilizando um Sistema de Informação Geográfica (SIG), que busca simular a realidade do espaço geográfico, permitindo armazenamento, manipulação e análise de dados geográficos num ambiente computacional.

O SIG empregado nesse artigo é representado por uma base georreferenciada para todas as quadras do município, construída a partir do mapeamento dasimétrico (explicado na seção metodológica) da distribuição domiciliar na capital em 2011. Em um segundo momento, o limite máximo de novos domicílios permitidos por lei é estimado, tomando-se como pressupostos: a ocupação de todos os lotes vagos em sua capacidade máxima domiciliar, instituída por lei em cada classe do zoneamento; e a demolição das edificações que possam, potencialmente, ceder lugar a novos edifícios residenciais também construídos em sua capacidade domiciliar máxima.

Os resultados mostram o número atual de domicílios e o máximo de domicílios que poderiam vir a se instalar em cada quadra do município se os pressupostos forem mantidos. As informações produzidas fornecem subsídios para informar instrumentos de planejamento, caminhos para discutir as dimensões da ocupação urbana de médio prazo, os limites potenciais da ocupação humana, as áreas preferenciais de adensamento e as implicações dessa ocupação para o planejamento da capital (TORRES, 2006; REIBEL; AGRAWAL, 2007; JANNUZZI, 2007; SANTOS, 2010). Além disso, os resultados propõem uma contribuição metodológica para estudos demográficos em pequenas áreas, ao possibilitar simulações espaciais em espaços intraurbanos para investigar cenários de demandas sociais, apontando onde a expansão e o adensamento urbano podem ocorrer, bem como o limite máximo suportado em cada quadra, caso os parâmetros de adensamento em cada classe de zoneamento previstos na Lei n. 9.959/10 sejam utilizados em sua totalidade (BELO HORIZONTE, 2010; PDDI, 2011).

A próxima seção traz uma síntese da expansão domiciliar em Belo Horizonte nos últimos anos, assim como os principais instrumentos reguladores do espaço urbano da capital. Em seguida, é feita a apresentação da metodologia e informações utilizadas na criação dos dois cenários de adensamento, complementada com os resultados, conclusões e considerações finais.

\section{Adensamento domiciliar e instrumentos reguladores do espaço urbano de Belo Horizonte}

O planejamento da ocupação do espaço é uma marca instaurada em Belo Horizonte desde a sua criação, em 1897, conferindo-lhe, segundo Matos (1992), o título de primeira capital planejada implantada no país. Desde seu surgimento, esteve presente a implantação de mecanismos voltados para o ordenamento do espaço urbano, embora a maioria provocou diversos efeitos colaterais que dificultaram a gestão urbana municipal (MATOS, 1992; EPAMINONDAS, 2006). 
Em 1976 foi lançada a Lei Municipal n. 2.662, também conhecida como Lei de Uso e Ocupação do Solo (Luos), a qual foi apontada por Ferreira (1999) como a primeira tentativa de ordenação da produção do meio urbano e que anunciou o fim da expansão urbana sem a efetiva presença de um processo de planejamento urbano. Em 1979, entrou em vigor a Lei Federal n. 6.766, que dispõe sobre o Parcelamento do Solo Urbano e definiu loteamentos e desmembramentos, além de ditar normas para os parcelamentos urbanos. A partir de então, todos os municípios brasileiros deveriam criar sua legislação de parcelamento do solo com base nos parâmetros desta Lei (BRASIL, 1979; CAVALCANTI, 1999).

Com a promulgação da Constituição Federal de 1988, o Plano Diretor Municipal (PDM) consolidou-se como um instrumento importante e obrigatório para o planejamento urbano dos municípios populosos. Os princípios que norteiam o PDM apareceram com maior robustez em 2001, com a criação do Estatuto da Cidade (BRASIL, 2005). O PDM de Belo Horizonte foi elaborado em 1996 (Lei n. 7.165), assim como a Lei de Parcelamento, Ocupação e Uso do Solo ou LPOUS (Lei n. 7.166). Por influência direta da Constituição Federal de 1988, as Leis instituídas em 1996 visavam a alteração da lógica de ocupação e de ordenamento do espaço urbano.

Em 2010 foi lançada, em Belo Horizonte, a Lei n. 9.959, que altera as Leis n. 7.165/96 e 7.166/96, de forma mais restritiva no que tange ao adensamento e à expansão urbana do município, que já contava com 2,37 milhões de habitantes e quase 800 mil domicílios (IBGE, 2011; BELO HORIZONTE, 2011a).

A análise da evolução da legislação municipal que trata da expansão urbana e adensamento do município permite diagnosticar que, apesar da maior restrição nos critérios de uso e ocupação do solo, a legislação vigente até 2010 possibilitou a saturação e conurbação do espaço urbano do município, assim como o aumento do número de domicílios por quadras (adensamento domiciliar) em níveis de verticalização incompatíveis com a infraestrutura urbana. 0 resultado foi a criação de problemas de difícil solução para a capital, tais como déficit habitacional, verticalização da paisagem e acúmulo de veículos. Segundo Lemos et al. (2004), como a mancha urbana ocupou praticamente todo o município, restou ao zoneamento da capital estimular o adensamento domiciliar nucleado, que prioriza a descentralização de atividades e que, espera-se, não condicione a uma contínua degradação da qualidade do ambiente urbano.

A Lei Municipal n. 9.959/10 (BELO HORIZONTE, 2010), que vigora atualmente, forneceu os parâmetros necessários para as simulações deste trabalho. Como o PDM e a LPOUS definem critérios e limites para o exercício do direito de propriedade, o principal instrumento utilizado para a definição do modo pelo qual a função social da propriedade deve ser cumprida é o zoneamento, que divide o território municipal em glebas, conforme critérios que atendem ao modelo de ordenamento territorial traçado. 0 zoneamento atual é dividido nas seguintes categorias: Zona de Preservação Ambiental (ZPA); Zona de Proteção (ZP); Zona de Adensamento Restrito (ZAR); Zona de Adensamento Preferencial (ZAP); Zona Central (ZC); Zona Adensada (ZA); Zona de Especial Interesse Social (Zeis); e Zona de Grandes Equipamentos (ZE). 
Os limites praticáveis nas edificações construídas em cada tipo de zoneamento são dados pelos valores dos parâmetros urbanísticos do PDM, sendo que a quota de terreno por unidade habitacional (QT), vinculada ao zoneamento, é o parâmetro da Lei n. 9.959/10, que define, para cada tipo de zona, o número máximo de domicílios comportado por lote. A QT é o instrumento que controla o nível de adensamento domiciliar nas edificações destinadas ao uso residencial ou na parte residencial das edificações de uso misto. 0 Quadro 1 apresenta os valores mínimos em $\mathrm{m}^{2}$ da QT permitida para cada domicílio em cada categoria do zoneamento descrita anteriormente (BELO HORIZONTE, 2010). A título de ilustração, um terreno de $800 \mathrm{~m}^{2}$ localizado no zoneamento ZA (QT de $40 \mathrm{~m}^{2} /$ un.) pode possuir no máximo 20 domicílios. Se este mesmo terreno estivesse localizado no zoneamento ZP-3 (QT de $200 m^{2} /$ un.), é possível a construção de até quatro domicílios.

QUADRO 1

Parâmetros urbanísticos relativos à quota de terreno por unidade habitacional por categoria de zoneamento Município de Belo Horizonte - 2011

\begin{tabular}{cc}
\hline Categoria do zoneamento & $\begin{array}{c}\text { Quota de terreno por unidade habitacional } \\
\left(\mathrm{m}^{2} / \text { un. }\right)\end{array}$ \\
\hline ZPAM & - \\
ZP-1 & 2.500 \\
ZP-2 & 1.000 \\
ZP-3 & 200 \\
ZAR-1 & 180 \\
ZAR-2 & 45 \\
ZA & 40 \\
ZAP & 40 \\
ZHIP & 8 \\
ZCBH & 20 \\
ZCBA & 25 \\
ZCVN & 25 \\
Zeis & - \\
ZE & - \\
\hline
\end{tabular}

Fonte: Belo Horizonte (2010).

\section{Metodologia}

Para o desenvolvimento da metodologia, foram definidas algumas estratégias com base nos textos de Cota (2002, 2010), Lemos et al. (2004) e PDDI (2011), na análise das Leis n. 7.165/96, 7.166/96 e 9.959/10, que tratam da evolução da legislação sobre o uso e ocupação do solo em Belo Horizonte, e em um processo de criação dos pressupostos e validação dos dados básicos pela equipe de técnicos da Secretaria Municipal Adjunta de Planejamento Urbano (SMAPU-PBH), no período 2011-2012. Assim:

- este trabalho simula a ocupação máxima somente nas classes de zoneamento que permitem construções do tipo "residencial”, caracterizado pelos domicílios. Classes 
de zoneamento dedicadas a ocupações do tipo "não residencial”, como indústria, comércio, serviços e equipamentos públicos, não foram consideradas passíveis de construções do tipo "residencial”, não sendo incorporadas na simulação;

- o processo de expansão domiciliar ocorrerá a partir da construção de novas edificações em lotes vagos ou em locais que possam ser demolidos, sendo que, sempre que o zoneamento aceitar, as novas construções serão do tipo apartamento e não do tipo casa;

- as Leis municipais n. 7.165/96, 7.166/96 e 9.959/10, referentes a parcelamento, ocupação e uso do solo no município, influenciarão diretamente na expansão das áreas urbanas e no adensamento dos espaços já ocupados:

- o zoneamento municipal não deve sofrer alterações;

- as categorias de zoneamento impróprias ao uso domiciliar não serão ocupadas por moradias;

- o adensamento domiciliar nas áreas de vilas e aglomerados (Zeis-1 e Zeis-3) continuará a ocorrer em ritmo parecido com o restante da capital;

- as quadras do município passíveis de ocupação, mas que não possuem lotes vagos ou edificações potenciais para demolição, manterão seu estoque domiciliar ao longo do tempo;

- o cenário de adensamento domiciliar utilizou a quota de terreno praticada pelo mercado imobiliário em vez daquela prevista na Lei n. 9.959/10, cujos valores estão em processo de revisão por não serem condizentes com a realidade do município;

- os grandes empreendimentos estruturadores do espaço no vetor norte da capital Linha Verde, Aeroporto Industrial de Confins, Cidade Administrativa do Governo do Estado e Anel Viário Norte - aumentarão a pressão sobre áreas passíveis de crescimento domiciliar em toda a porção setentrional do município;

- a região do Isidoro passará, na próxima década, por um intenso processo de adensamento domiciliar, pois possui um Plano de Urbanização que permite um aumento de até 67 mil novos domicílios.

Os próximos tópicos apresentam uma descrição mais detalhada do processo de simulação da capacidade de adensamento domiciliar de Belo Horizonte.

Uso do SIG e mapeamento dasimétrico para projetar a capacidade de carga urbana

Reunindo dados relevantes para esta pesquisa, foi construído um SIG cujo conteúdo será descrito adiante. Para conferir maior precisão às análises que envolvem a densidade de parâmetros, como o número de domicílios ou a população em cada quadra, utilizou-se a técnica de mapeamento dasimétrico, que consiste em distribuir valores conhecidos para uma unidade espacial de referência apenas sobre partes de sua área em que se sabe que o fenômeno se manifesta (EICHER; BREWER, 2001; MENNIS; HULTGREN, 2006). Por 
exemplo, conhecendo a população de um setor censitário e sabendo que ela se concentra nas quadras e lotes residenciais, é possível excluir da distribuição espacial as áreas de outra natureza (arruamento, parques, canteiros, praças, indústrias e áreas comerciais não habitadas). Esta técnica pode ser considerada uma sofisticação de um mapa coroplético (mapa temático poligonal convencional), pois utiliza dados auxiliares para refinar a representação da distribuição espacial da variável analisada.

A metodologia apresentada a seguir foi elaborada e validada em conjunto com os técnicos da Secretaria Municipal Adjunta de Planejamento Urbano de Belo Horizonte (SMAPU). ${ }^{3}$ Todas as informações vetoriais adquiridas passaram por um processo de compatibilização das bases de dados, utilizando o programa MapInfo 11. Inicialmente, os arquivos georreferenciados tiveram seu limite geográfico adaptado de forma a corresponder à delimitação oficial do município de Belo Horizonte. Em um segundo momento, todos os arquivos com as malhas digitais foram ajustados à projeção geográfica UTM (Universal Transversa de Mercator), Fuso 23 Sul, Datum SIRGAS 2000.

A Figura 1 mostra a estrutura desenvolvida para três porções distintas do município (região do Isidoro, região das Zeis e demais áreas), possibilitando a criação dos cenários que compõem o artigo, descritos na próxima seção.

FIGURA 1

Etapas do processo de criação dos cenários de simulação do número máximo de domicílios para a área urbana de Belo Horizonte em ambiente SIG

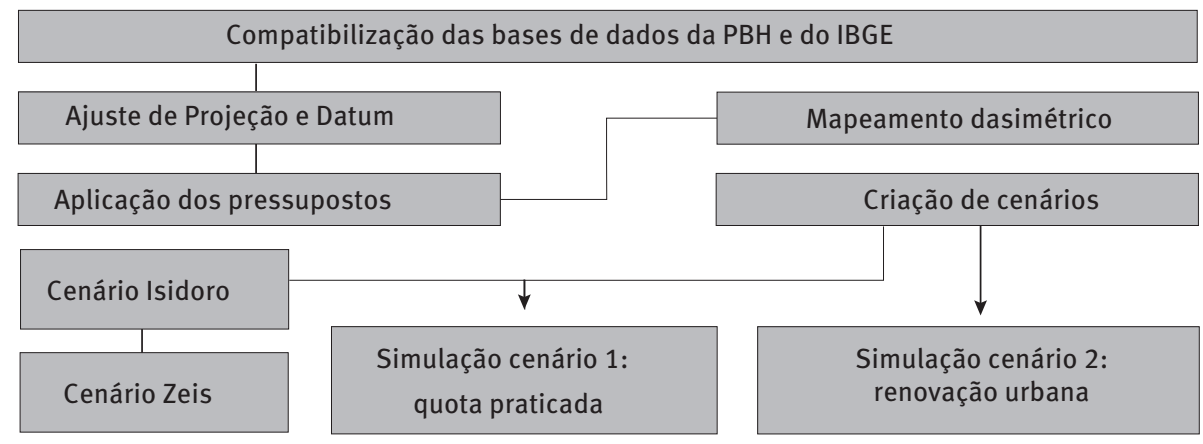

Bases de dados utilizadas nas simulações

O Quadro 2 traz as informações básicas disponibilizadas pela Prefeitura de Belo Horizonte e pelo IBGE, que serviram de insumos para as estimativas de número máximo de domicílios possível a partir da aplicação da lei municipal vigente. Cada informação apresentada neste quadro é uma base de dados georreferenciada sobre uso e ocupação do solo de Belo Horizonte.

\footnotetext{
${ }^{3}$ As bases de dados cadastrais da capital foram gentilmente cedidas pela SMAPU-PBH, para uso exclusivo na realização desta pesquisa. Os resultados deste trabalho estão sendo utilizados pela Prefeitura de Belo Horizonte para subsidiar os nove Planos Diretores das Regionais de Planejamento do município.
} 
QUADRO 2

Variáveis e origem (bases de dados) utilizadas como insumo para a simulação do número máximo de domicílios para a área urbana de Belo Horizonte

\begin{tabular}{|c|c|}
\hline $\begin{array}{l}\text { Informações / bases } \\
\text { georreferenciadas }\end{array}$ & Descrição \\
\hline Quadras & $\begin{array}{l}\text { A base de quadras de Belo Horizonte, referente ao Cadastro Técnico } \\
\text { Municipal (CTM) de setembro de } 2011 \text { (BELO HORIZONTE, 2011b), é uma } \\
\text { base vetorial formada por } 17.448 \text { polígonos que correspondem a todas } \\
\text { as quadras do município, com informações atualizadas segundo a Lei } \\
\text { n. } 9.959 / 10 \text {. }\end{array}$ \\
\hline Regional de Planejamento & $\begin{array}{l}\text { A base atualizada com as delimitações das Regionais de Planejamento } \\
\text { da capital foi extraída do Cadastro Técnico Municipal (CTM) de setembro } \\
\text { de } 2011 \text { (BELO HORIZONTE, 2011c) e possui nove polígonos que foram } \\
\text { utilizados para possibilitar uma interpretação dos resultados por } \\
\text { regional. }\end{array}$ \\
\hline Cadastro de contribuintes do IPTU & $\begin{array}{l}\text { A base de faces dos lotes de Belo Horizonte, referente a setembro de } \\
\text { 2011, foi extraída do cadastro do Imposto sobre a Propriedade Predial } \\
\text { e Territorial Urbana (BELO HORIZONTE, 2011b). Trata-se de uma base } \\
\text { vetorial formada por } 705.850 \text { linhas que correspondem a todas as faces } \\
\text { de lotes do município, com informações utilizadas para a coleta do } \\
\text { IPTU. Cada face possui os seguintes atributos: área do terreno em m²; } \\
\text { área construída no terreno em m²; tipo de ocupação (residencial, não } \\
\text { residencial e territorial); tipo construtivo (casa, barracão, apartamento, } \\
\text { área comercial e lote vago); e quantidade de domicílios por registro. } \\
\text { Para a criação de uma evolução temporal das informações, foram } \\
\text { utilizadas as mesmas bases com as datas de referência em julho de } \\
2006 \text { e agosto de } 2010 \text {. }\end{array}$ \\
\hline Zoneamento & $\begin{array}{l}\text { O zoneamento de Belo Horizonte em setembro de } 2011 \text { (BELO } \\
\text { HORIZONTE, 2011d) é representado por uma base vetorial formada } \\
\text { por } 16.492 \text { polígonos que correspondem a todas as manchas de } \\
\text { zoneamento do município, com informações atualizadas conforme a Lei } \\
\text { n. } 9.959 / 10 \text {. Cada mancha possui atributos referentes ao zoneamento } \\
\text { específico, que pode englobar uma porção ou a área total de cada } \\
\text { quadra do município. }\end{array}$ \\
\hline Tipologias de ocupação & $\begin{array}{l}\text { As informações georreferenciadas de tipologias de ocupação foram } \\
\text { extraídas do CTM de setembro de } 2011 \text { (BELO HORIZONTE, 2011c) e } \\
\text { são formadas por } 336.051 \text { polígonos que representam todos os lotes } \\
\text { cadastrados do município, com informaç̧ões sobre a tipologia de } \\
\text { ocupação do lote, ano de construção, quantidade de pavimentos da } \\
\text { edificação, tipo de uso e área do lote. }\end{array}$ \\
\hline Setores censitários & $\begin{array}{l}\text { Os arquivos georreferenciados referentes aos setores censitários (SCS) } \\
\text { dos Censos de } 2000 \text { e } 2010 \text { (IBGE, 2002, 2011) foram utilizados de } \\
\text { forma complementar, para suprir informações das áreas de vilas e } \\
\text { favelas do município, que possuem baixa cobertura no cadastro do } \\
\text { IPTU. }\end{array}$ \\
\hline
\end{tabular}

Fonte: Belo Horizonte (2011b, 2011c, 2011d), IBGE (2011).

Na Figura 2, o primeiro mapa mostra os limites das nove Regiões de Planejamento e as 17.155 quadras da capital e o segundo apresenta as 19.008 manchas que formam as 15 categorias de zoneamento presentes na Lei n. 9.959/10, as quais representam as unidades referidas na lei com os valores permitidos para construção residencial. 
FIGURA 2

Regiões de Planejamento, quadras e zoneamento atualizados pela Lei 9.959/10 Município de Belo Horizonte - 2011

$$
\text { Quadras }
$$

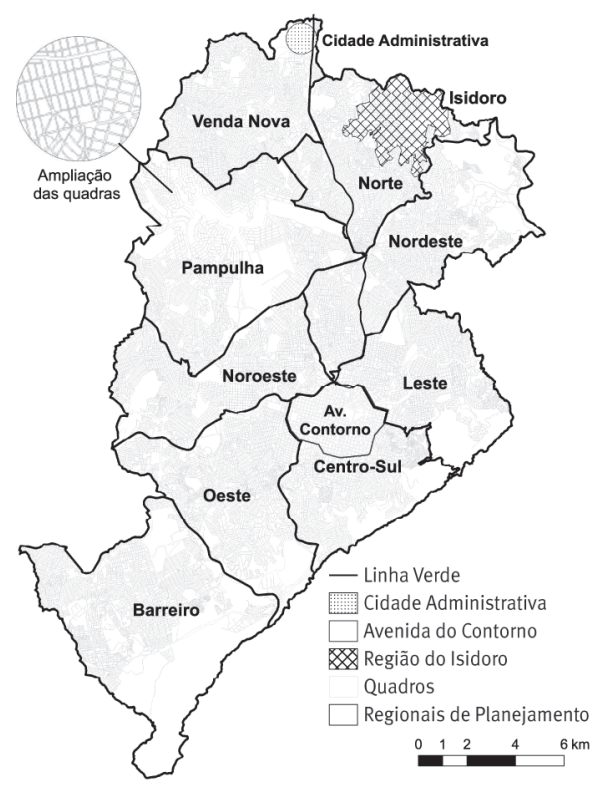

Zoneamento

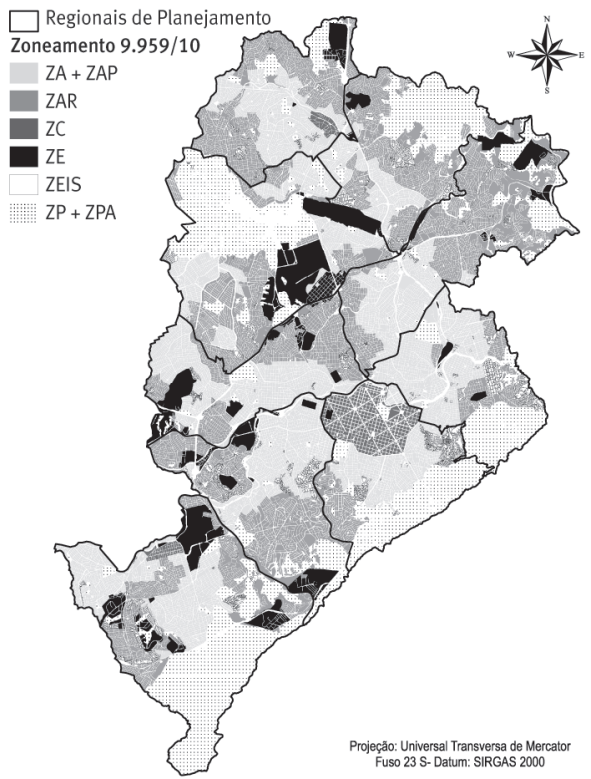

Fonte: Belo Horizonte (2011b, 2011c, 2011d), IBGE (2011).

\section{Adensamento domiciliar de Belo Horizonte}

Os cenários construídos neste artigo buscaram projetar o número máximo de domicílios que podem vir a ser edificados em Belo Horizonte, adotando-se como pressuposto que todas as áreas vazias e com potencial de reconstrução sejam utilizadas para fins de habitação. Inicialmente, foi necessária a aplicação do mapeamento dasimétrico para o ajuste de todas as bases de informação, de tal forma que houvesse uma perfeita sobreposição espacial entre todas as bases de dados e que todas as informações possuíssem atributos devidamente preenchidos. Para a criação dos cenários, foram realizadas as seguintes etapas de manipulação das informações: ${ }^{4}$

- divisão da base de cadastro do IPTU segundo a variável "tipo de construção" em dois arquivos: "IPTU residencial" e "IPTU territorial”, com a exclusão dos dados não residenciais (lojas, salas, galpões, etc.);

- compatibilização dos vetores com sobreposição espacial na base IPTU residencial, como no caso dos edifícios e condomínios;

- ajuste da área dos lotes que possuíam área maior do que a quadra ou que estavam muito discrepantes na amostra;

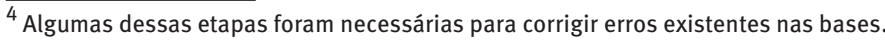


- verificação manual e retirada da maioria dos lotes cujo tamanho é $60 \%$ superior ao tamanho total da quadra na qual ele está inserido, o que permitiu localizar antigos loteamentos que foram divididos em glebas menores e ainda não haviam sido excluídos da base cadastral da Prefeitura;

- exclusão de todos os lotes vagos nos zoneamentos ZE, ZPAM, Zeis-1 e Zeis-3, uma vez que a Lei n. 9.959/10 não permite que estes espaços sejam edificados com novos domicílios;

- exclusão de todos os lotes vagos sobrepostos às bases de áreas verdes (áreas protegidas, Programa BH Verde, Parques Municipais atuais e futuros, Reserva Particular Ecológica);

- exclusão de todos os lotes vagos da base do IPTU que não fossem sobrepostos à categoria de uso "lote vago" ou "nulo (existe lote mas sem cadastro no IPTU)" da base do CTM; ${ }^{5}$

- exclusão de lotes vagos com projetos de construção aprovados pela PBH: 236 lotes vagos com projetos aprovados do tipo não residencial; e 1.814 lotes vagos com projetos aprovados do tipo residencial; ${ }^{6}$

- justaposição das bases “IPTU residencial” e “IPTU territorial” com a base de quadras. Cálculo para cada quadra: área total $\left(\mathrm{m}^{2}\right)$ dos terrenos residenciais; área total construída $\left(\mathrm{m}^{2}\right)$ nos terrenos residenciais; quantidade total de domicílios; quantidade de casas, barracões e apartamentos; quantidade de lotes vagos; área total $\left(\mathrm{m}^{2}\right)$ dos lotes vagos; e área total $\left(\mathrm{m}^{2}\right)$ da quadra;

- exclusão das quadras com os zoneamentos ZE, ZPAM e Zeis. Para o caso das Zeis, foi elaborado um método específico, descrito adiante.

Após todos os ajustes, foi construído um cenário de adensamento via lotes vagos apresentado a seguir.

\section{Cenário 1: ocupação dos lotes vagos utilizando a quota praticada}

O cenário 1 apresenta para cada quadra o quantitativo máximo de domicílios que pode ocorrer, caso os lotes vagos desta quadra sejam adensados usando a QT média de cada quadra praticada pelo mercado imobiliário entre 2008 e 2011. A justificativa de criação deste cenário 1 se deu pelo fato, comprovado a partir da análise das informações cadastrais, de que a dinâmica do mercado imobiliário do município pratica uma quota de terreno usualmente mais elevada do que a prevista na Lei n. 9.959/10.

\footnotetext{
${ }_{5}^{5}$ Para esses lotes excluídos, foi calculado o número de domicílios, extraídos da base do CTM. Os resultados foram incorporados à base "IPTU residencial", dado que esses "lotes vagos" já estão ocupados e não estão atualizados no cadastro do IPTU.

${ }^{6}$ Para esses lotes excluídos, foi calculado o número de domicílios, extraídos do cadastro de unidades planejadas existente na base de Projetos Aprovados da PBH. Os resultados foram incorporados à base "IPTU residencial”, dado que esses "lotes vagos" já possuem planejamento de uso domiciliar.
} 
O cálculo da QT praticada pelo mercado imobiliário do município foi realizado a partir da divisão da área total do lote da edificação do Cadastro Técnico Municipal pela quantidade de domicílios cadastrados no lote. Os resultados foram refinados segundo a análise anual da evolução da QT praticada em cada quadra, entre 1970 e 2011, para o total de domicílios, assim como para as construções do tipo casa e apartamento. A evolução temporal da média por quadra das QT praticadas pelo mercado é apresentada na Tabela 1. Os dados apontam, para o total municipal, uma tendência nas últimas duas décadas de diminuição da quota praticada, principalmente nos domicílios do tipo apartamento. Nesse contexto, os valores obtidos para apartamentos no período de 2008 a 2011, mais próximos do praticado atualmente pelos agentes imobiliários, foram escolhidos como parâmetro para calcular a QT de cada quadra que irá integrar a razão de adensamento do cenário 1.

TABELA 1

Média da quota de terreno praticada, segundo tipos de domicílio Município de Belo Horizonte - 1970-2011

\begin{tabular}{lccccc}
\hline \multirow{2}{*}{ Tipos de domicílio } & \multicolumn{5}{c}{ Quota média (em m²/domicílio) } \\
\cline { 2 - 5 } & 1970-1980 & $1981-1990$ & $\mathbf{1 9 9 1 - 2 0 0 0}$ & $\mathbf{2 0 0 1 - 2 0 0 7}$ & $\mathbf{2 0 0 8 - 2 0 1 1}$ \\
\hline Total de domicílios & $\mathbf{2 1 7 , 6}$ & $\mathbf{2 2 6 , 6}$ & $\mathbf{2 2 4 , 9}$ & $\mathbf{2 1 9 , 5}$ & $\mathbf{1 7 4 , 1}$ \\
Domicílios do tipo casa & 225,6 & 236,4 & 258,0 & 283,3 & 274,7 \\
Domicílios do tipo apartamento & 63,2 & 63,1 & 68,7 & 62,8 & 60,8 \\
\hline
\end{tabular}

Fonte: Belo Horizonte (2011a).

Também confirmam o pressuposto descrito anteriormente os dados referentes ao número de domicílios particulares permanentes captados nos Censos Demográficos de 2000 e 2010 (IBGE 2002, 2011). Uma análise pormenorizada mostrou que, na última década, a taxa de crescimento geométrico anual (TCG) dos apartamentos foi de 4,0\% ao ano, contra 0,9\% para os domicílios do tipo casa. Entre 2000 e 2010, o número de casas no município aumentou em 41 mil unidades, passando de 458.893 para 499.867 , enquanto o de apartamentos ampliou-se em 81 mil unidades (de 169.554 para 251.275).

Para as quadras que não tiveram construção do tipo apartamento entre 2008 e 2011, foi calculada a média de QT praticada em cada zoneamento, dentro de cada Regional de Planejamento do município, de tal forma a se obter uma QT média para cada espaço intraurbano.

A única exceção foi feita para as quadras localizadas nas tipologias ZP-1 e ZP-2, que seguiram as diretrizes previstas na Lei n. 9.959/10. Dessa forma, para as quadras inseridas na categoria ZP-1, a QT foi calculada da seguinte forma:

- QT de $2.500 \mathrm{~m}^{2} / \mathrm{un}$. para lotes com área maior ou igual a $2.500 \mathrm{~m}^{2}$;

- QT do tamanho do terreno para lotes com área menor que $2.500 \mathrm{~m}^{2}$.

Para as quadras inseridas em ZP-2, a QT foi calculada da seguinte forma:

- QT de $1.000 \mathrm{~m}^{2} / \mathrm{un}$. para lotes com área maior ou igual a $1.000 \mathrm{~m}^{2}$;

- QT do tamanho do terreno para lotes com área menor que $1.000 \mathrm{~m}^{2}$. 
Feitas todas as ressalvas, o cálculo do número de domicílios no cenário 1 foi realizado a partir da seguinte razão de adensamento:

(Lv Iptu / quota praticada) + EcTot

onde:

Lv Iptu = área em $\mathrm{m}^{2}$ disponível para construção domiciliar na quadra;

Quota praticada $=$ quota de terreno por unidade habitacional $\left(\mathrm{m}^{2} / \mathrm{un}\right.$.) praticada na quadra ou no zoneamento por regional (onde não existia informação por quadra);

EcTot $=$ total de domicílios existentes em setembro de 2011.

Devido às diversas possibilidades de adensamento presentes no meio urbano da capital, este cenário teve que ser adaptado a duas peculiaridades existentes que são detalhadas a seguir.

Complemento ao cenário 1: cálculo dos domicílios atuais e futuros das categorias Zeis-1 e Zeis-3

O mapeamento dasimétrico dos setores censitários de 2000 e 2010 mostrou-se mais preciso para gerar as informações domiciliares para as quadras cobertas pelos zoneamentos Zeis-1 e Zeis-3, que representam as vilas e aglomerados distribuídos ao longo de todo o município. Este mapeamento apresentou-se mais confiável em função da imprecisão dos registros da Prefeitura de Belo Horizonte sobre a população residente nas áreas de vilas e favelas.

Para o cenário 1, que segue as tendências de adensamento domiciliar da capital, foi constatado que o número de domicílios nas Zeis cresceu na última década a uma TCG de $1,82 \%$ ao ano, valor ligeiramente inferior à taxa de 1,94\% ao ano, referente ao total de domicílios do município. Entre 2000 e 2010, o número de moradias nessas zonas passou de 83.455 para 99.964 (IBGE, 2002, 2011). Isso representa um diferencial de 16,5 mil domicílios, demonstrando que essas áreas continuam em processo de crescimento domiciliar, ao contrário do que é desejado nos instrumentos urbanísticos previstos no Estatuto das Cidades e na Lei n. 9.959/10.

A primeira etapa necessária para o cálculo de adensamento das Zeis foi a compatibilização dos setores censitários de 2000 e 2010, conforme a metodologia desenvolvida por Umbelino (2007). Após a compatibilização, o mapeamento dasimétrico foi utilizado nos setores, conforme pode ser verificado na Figura 3. 0 primeiro mapa mostra o limite de todos os setores censitários, enquanto o segundo apresenta o resultado após estes terem sua área total filtrada pela subtração das áreas de preservação, arruamento, equipamentos públicos e locais de comércio/serviços, de tal forma que se obteve a área líquida de cada setor (ocupada somente por moradias). Dessa forma, 3.935 setores censitários de 2010 foram unificados com os 2.563 setores censitários de 2000, resultando em uma base de 3.880 polígonos que representam a área ocupada por domicílios na capital. Esse procedimento possibilitou a análise temporal dos dados censitários na menor escala de desagregação possível. 
O próximo ajuste foi a adaptação das informações censitárias de agosto de 2010 para a data de referência dessa pesquisa, por meio da extrapolação da TCG de cada setor entre 2000 e 2010, o que resultou em uma estimativa de 101.723 domicílios existentes nas Zeis em setembro de 2011.

FIGURA 3

Setores censitários compatibilizados antes e após o mapeamento dasimétrico, para a estimativa domiciliar das Zeis

Município de Belo Horizonte - 2011

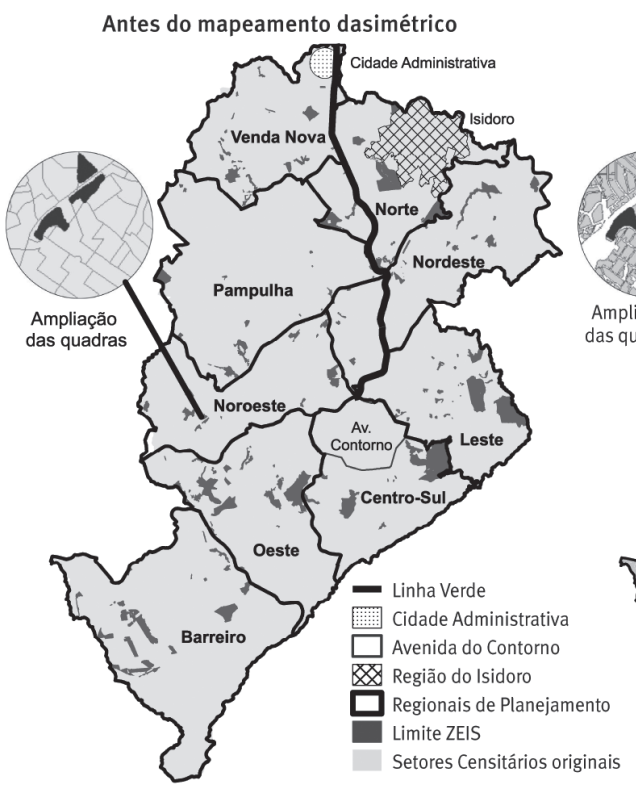

Após o mapeamento dasimétrico

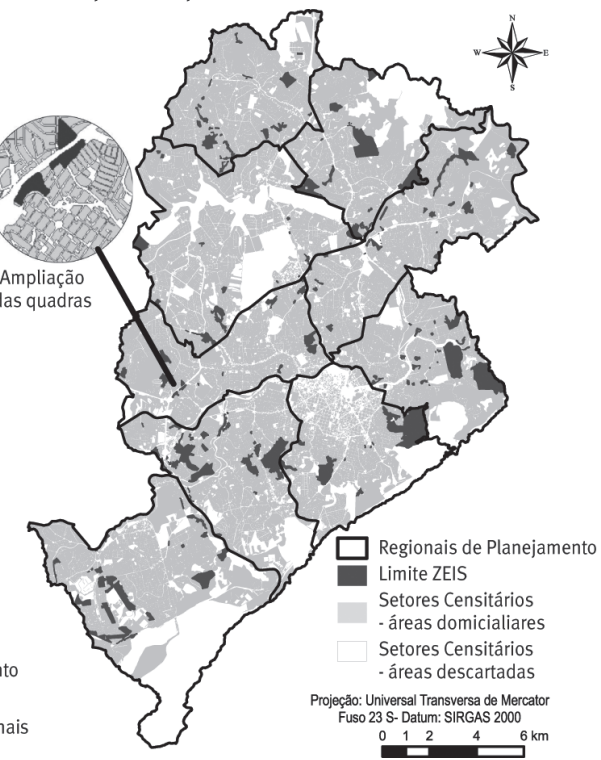

Fonte: Belo Horizonte (2011b, 2011c, 2011d), IBGE (2011).

Para o cálculo dos domicílios futuros que podem surgir nas Zeis, via construção nas áreas vagas ou adensamento domiciliar (também conhecidos como "puxadinhos"), foram adotados os procedimentos apresentados a seguir.

Construção nas áreas vagas:

- a partir da área não ocupada $\left(\mathrm{m}^{2}\right)$ em 2011 em cada quadra e da densidade média domiciliar de ocupação (9.387 dom./ $\mathrm{km}^{2}$ ) das Zeis, foi calculado o número aproximado de domicílios que cada quadra ainda comportaria, caso essa densidade média fosse aplicada na área não ocupada.

Adensamento (verticalização):

- para as quadras com TCG nula ou negativa entre 2000 e 2011 foi adotado o pressuposto de que o adensamento não ocorrerá nesses locais;

- para as quadras com TCG positiva e acima da densidade domiciliar média (9.387 dom. $/ \mathrm{km}^{2}$ ), também foi adotado o pressuposto de que o adensamento da quadra na área construída não ocorrerá, dado que o espaço edificado já está saturado; 
- nas quadras com TCG positiva e abaixo da densidade domiciliar média, foi calculado o número de domicílios que ainda podem surgir (puxadinhos), caso o adensamento médio seja atingido nessas quadras.

Complemento ao cenário 1: cálculo dos domicílios futuros para a região do Isidoro

A porção norte do município de Belo Horizonte é uma região que, nos últimos anos, tem vivenciado forte pressão do mercado imobiliário em função de diversos investimentos, como a implantação da Cidade Administrativa, a criação da Linha Verde e a reestruturação do aeroporto de Confins (BELO HORIZONTE, 2010; COTA, 2010; PDDI, 2011). A região do Isidoro localiza-se no extremo norte da capital, na Regional de Planejamento Norte. Além de possuir uma localização estratégica no contexto metropolitano, o local caracteriza-se por estar predominantemente desocupado, sendo a última grande fronteira de expansão urbana de Belo Horizonte, com a maior porção de terra contínua passível de parcelamento existente no município, em uma área de 9,6 km² (BELO HORIZONTE, 2010).

Para minimizar a ocupação desordenada do local, a Prefeitura elaborou o segundo Plano Urbano Ambiental da Região do Isidoro, que visa promover, após 2015, a proteção e recuperação ambiental da região, por meio de um processo de ocupação ordenado (BELO HORIZONTE, 2010; COTA, 2010). As diretrizes do Plano preveem, para a próxima década, a construção de um contingente máximo de 67.623 domicílios (cenário adensamento populacional máximo), que foi adotado como pressuposto para integrar os resultados da região do Isidoro, presentes no cenário 1 (BELO HORIZONTE, 2011b).

\section{Cenário 2: renovação urbana via demolições}

0 cenário 2 , diferentemente dos pressupostos do cenário 1 , visa simular o máximo de domicílios que podem surgir no município, oriundos da renovação urbana, ou seja, caso todos os domicílios com potencial de demolição cedam lugar a novas edificações residenciais construídas em sua capacidade domiciliar máxima.

0 primeiro procedimento para simular o processo de renovação urbana domiciliar foi adotar como pressuposto a criação de um único cenário, tomando-se como parâmetro a QT praticada pelo mercado imobiliário. Em seguida, foi analisada a evolução temporal das bases do tipo residencial do cadastro de contribuintes do IPTU, referentes a julho de 2006, agosto de 2010 e setembro de 2011. Na comparação entre a localização espacial e o número do CTM das três bases, encontraram-se as edificações do tipo apartamento existentes em 2011 que, nos períodos anteriores, eram casas, barracões ou edificações do tipo apartamento, mas com número menor de moradias do que em 2011. Acredita-se que dessa forma tenha sido possível captar todas as demolições recentes ocorridas no município em prol da renovação urbana.

Os dados cadastrais revelaram que, em todo o período analisado, ocorreram 700 alterações em registros de edificações do município, originando 11.373 novos domicílios que podem ser caracterizados como oriundos da renovação urbana. Entre 2006 e 2010, 
509 registros de edificações foram renovados, originando 6.736 domicílios. Entre 2010 e 2011, 191 registros de edificações foram renovados, gerando 4.637 domicílios.

$\mathrm{Na}$ Figura 4, elaborada a partir da espacialização das referidas edificações, o primeiro mapa apresenta a mancha de influência de demolições, criada por meio do método de análise espacial Distance ${ }^{7}$ existente no programa Idrisi, sendo estimados 500 metros a partir de cada edificação com potencial de demolição. No segundo mapa, estas informações foram filtradas pela sobreposição desta mancha com as categorias de zoneamento que permitem a renovação urbana. 0 produto final foi uma área denominada zona potencial de renovação urbana.

FIGURA 4

Mancha de influência de demolições por zoneamento e zona potencial de renovação urbana, passível de demolições Município de Belo Horizonte - 2011

Mancha de influência de demolições

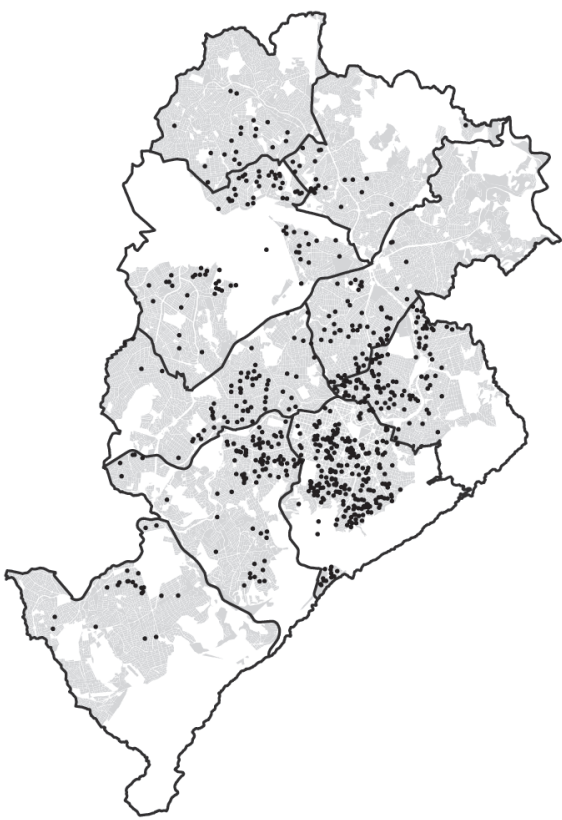

Zona potencial de renovação urbana

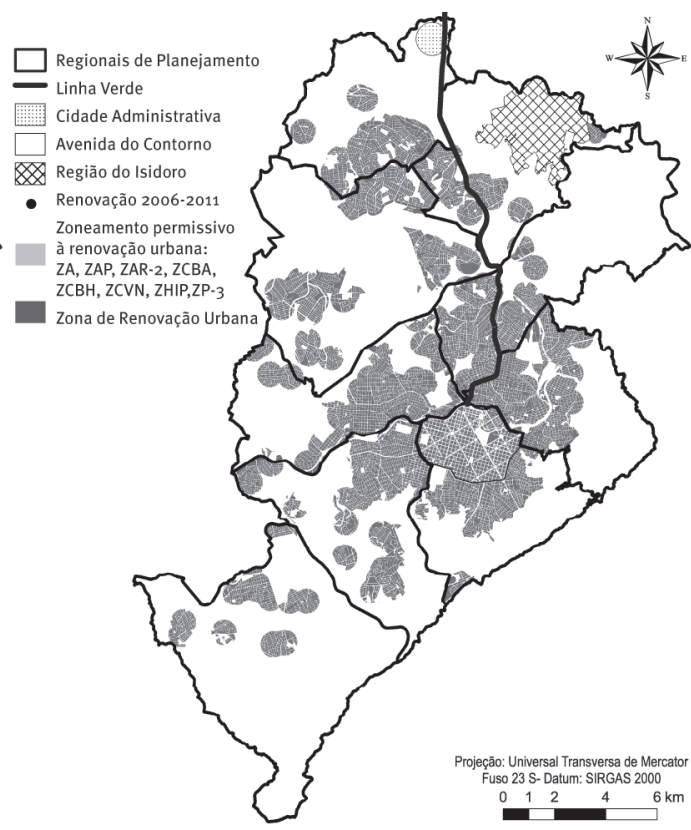

Fonte: Belo Horizonte (2011b, 2011c, 2011d), IBGE (2011).

Como a maioria dos domicílios localizados na zona potencial de renovação urbana não necessariamente será demolida, o próximo passo foi detectar características das edificações que as tornassem passíveis de demolição. Para isso, foram analisados padrões comuns nas variáveis disponíveis no SIG das edificações que sofreram renovação urbana entre 2006 e 2011. Foi feita a remoção de toda edificação dentro da zona de renovação urbana que: foi

\footnotetext{
${ }^{7}$ Módulo do programa Idrisi que calcula a distância euclidiana de cada célula da imagem às células analisadas, permitindo a obtenção de áreas de influência na forma de anéis concêntricos, ou buffers (EASTMAN, 2009).
} 
construída após o ano 2000; possui área do lote inferior a $360 \mathrm{~m}^{2}$; possui alto padrão de acabamento construtivo (padrão P5); tem mais de dez domicílios por lote; possui quatro ou mais pavimentos; e não seja classificada na base de tipologia de ocupação como Zeis, clubes, equipamentos de saúde e instituições religiosas.

\section{Resultados}

Apesar de todos os resultados das simulações terem sido obtidos na escala de quadras, para fins de análise optou-se pela agregação dos dados por Regional de Planejamento. A Tabela 2 apresenta o número de domicílios existentes na planta cadastral de Belo Horizonte e os resultados, para os dois cenários de simulação, do número potencial de domicílios a serem adicionados a Belo Horizonte ao longo do tempo.

TABELA 2

Domicílios existentes na planta cadastral e potenciais domicílios a serem construídos, por cenários simulados, segundo Regional de Planejamento Município de Belo Horizonte - 2011

\begin{tabular}{|c|c|c|c|c|c|}
\hline \multirow[b]{2}{*}{ Regional } & \multirow[b]{2}{*}{$\begin{array}{l}\text { Domicílios } \\
\text { existentes }\end{array}$} & \multirow[b]{2}{*}{ Lotes vagos } & \multicolumn{2}{|c|}{ Domicílios a serem construídos } & \multirow[b]{2}{*}{$\begin{array}{c}\text { Total (domicílios } \\
\text { existentes + } \\
\text { cenários } 1 \text { e } 2 \text { ) }\end{array}$} \\
\hline & & & $\begin{array}{c}\text { Cenário } 1 \\
\text { (quota praticada) }\end{array}$ & $\begin{array}{l}\text { Cenário } 2 \\
\text { (renovação } \\
\text { urbana) }\end{array}$ & \\
\hline Barreiro & 76.630 & 2.241 & 22.712 & 27.039 & 126.381 \\
\hline Centro-Sul & 132.930 & 2.145 & 13.467 & 19.227 & 165.624 \\
\hline Leste & 77.062 & 780 & 10.788 & 60.377 & 148.227 \\
\hline Nordeste & 88.243 & 3.230 & 46.458 & 34.274 & 168.975 \\
\hline Noroeste & 88.399 & 1.258 & 7.732 & 36.264 & 132.395 \\
\hline Norte (sem Isidoro) & 61.017 & 2.306 & 21.875 & 27.605 & 110.497 \\
\hline Oeste & 114.238 & 2.439 & 33.312 & 36.097 & 183.647 \\
\hline Pampulha & 87.313 & 4.479 & 31.316 & 54.015 & 172.644 \\
\hline Venda Nova & 73.108 & 1.846 & 14.850 & 41.442 & 129.400 \\
\hline Norte (só Isidoro) & - & - & 67.623 & - & 67.623 \\
\hline Total & 798.940 & 20.724 & 270.133 & 336.340 & 1.405 .413 \\
\hline
\end{tabular}

Fonte: Belo Horizonte (2011a, 2011b, 2011c, 2011d).

Os resultados das simulações (representados pela densidade de quadras/hectare) podem ser visualizados nas Figuras 5 e 6, que apresentam, respectivamente, o adensamento domiciliar de Belo Horizonte em 2011 e o somatório dos domicílios de 2011 com os cenários 1 e 2, mostrando as quadras do município que podem ter maior pressão em termos de adensamento domiciliar futuro. 
FIGURA 5

Domicílios por hectare existentes por quadra na planta cadastral Município de Belo Horizonte - setembro de 2011

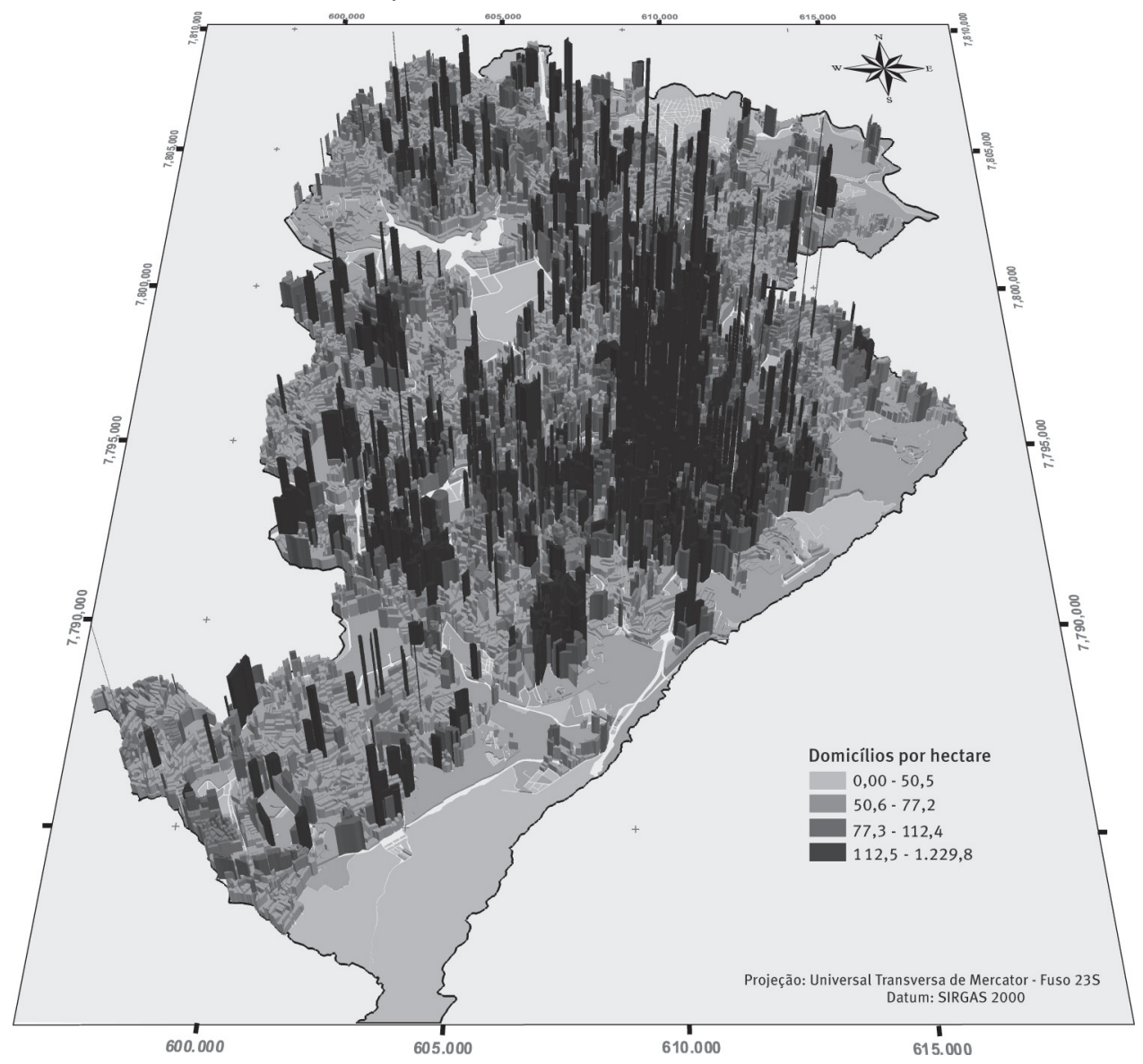

Fonte: Belo Horizonte (2011a, 2011b, 2011c, 2011d), IBGE (2011). 
FIGURA 6

Capacidade máxima domiciliar (domicílios por hectare por quadra) suportada a partir do somatório dos domicílios existentes com os casos de simulação 1 e 2

Município de Belo Horizonte - 2011

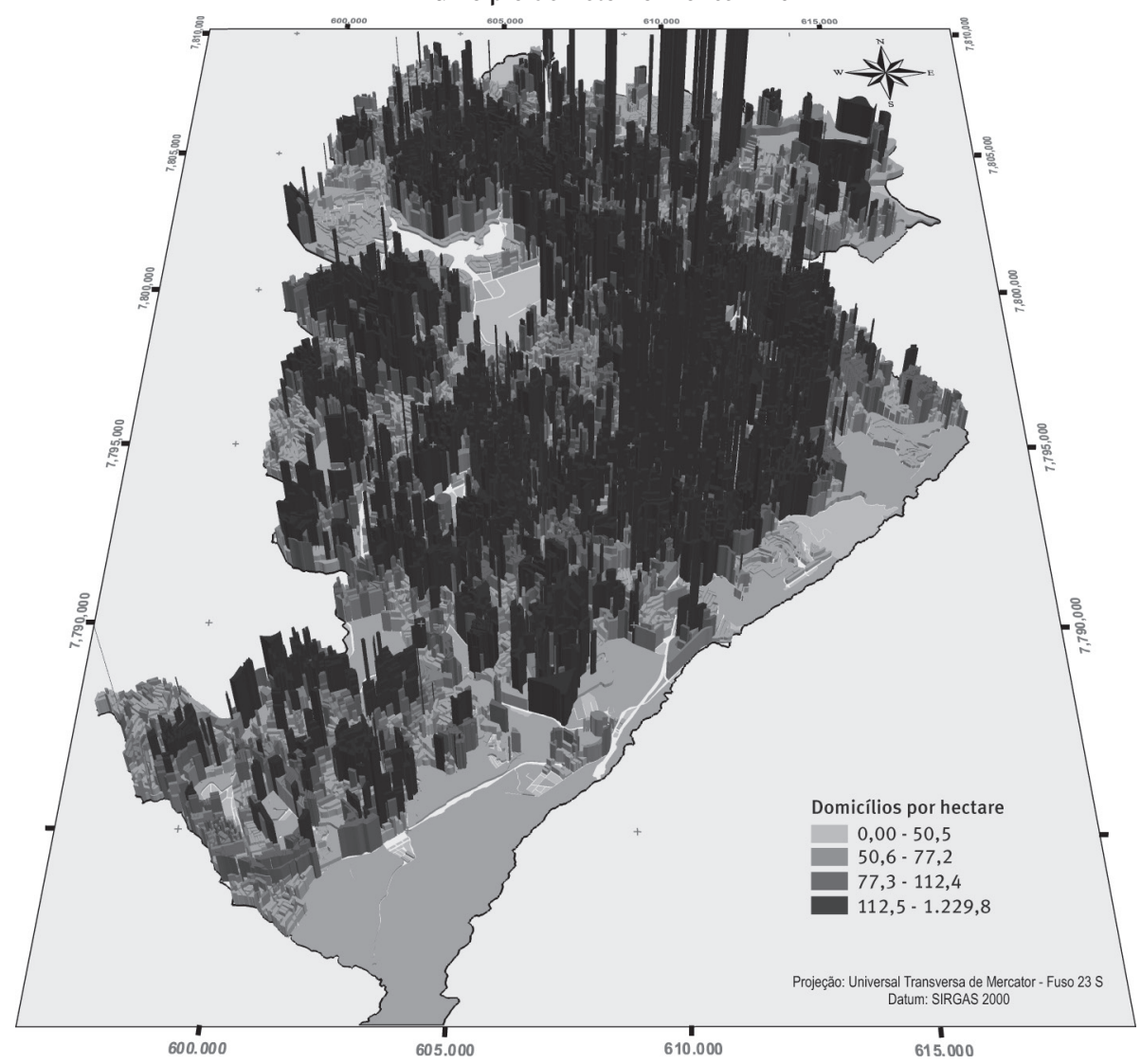

Fonte: Belo Horizonte (2011a, 2011b, 2011c, 2011d), IBGE (2011).

Analisando a área total proveniente da soma das 17.155 quadras do município, verificou-se que 3,1\% encontram-se em algum tipo de zoneamento que proíbe a construção de novas edificações, $14,6 \%$ são formadas por Zeis e $82,3 \%$ situam-se em regiões passíveis de adensamento ou demolição. Além das áreas de Zeis e da região do Isidoro, existem 5.195 quadras em Belo Horizonte com lotes vagos onde é possível a materialização do cenário 1 e 6.453 quadras onde os dados do cenário 2 podem se concretizar.

A análise do SIG construído a partir da junção das informações possibilitou quantificar 798.359 habitações na capital em 2011. De acordo com o cruzamento dos dados apresentados na Tabela 2, o resultado das simulações aponta que o município ainda comporta 270.133 moradias no cenário 1 e 336.340 no cenário 2. Em termos percentuais, o cenário 1 pode ocasionar um aumento de $33,8 \%$ no número de domicílios da capital, enquanto 0 cenário 2 prevê o a geração de 42,1\% novos domicílios via demolição. Nesse sentido, os 14.898 lotes vagos analisados ainda comportam um crescimento de aproximadamente 
$40 \%$ do número de domicílios da capital, caso o espaço urbano seja ocupado em sua potencialidade máxima.

A partir de uma interpretação integrada dos cenários, acredita-se que uma situação mais plausível poderia ocorrer a partir da junção do adensamento via QT praticada (cenário 1), com a renovação urbana (cenário 2), o que permitiria que Belo Horizonte aumentasse 0 número de domicílios em $75,9 \%$, chegando a atingir sua capacidade máxima de adensamento em cerca de 1.405 .413 moradias. Analisando esses valores por Regionais de Planejamento, verifica-se que a maior concentração pode ocorrer na regional Oeste (183.647 domicílios), seguida pelas regionais Norte (178.120), ${ }^{8}$ Pampulha (172.644 domicílios), Nordeste (168.975 domicílios) e Centro-Sul (165.624 domicílios). Estes resultados devem ser analisados pelo poder público com muita cautela, pois, apesar de serem hipotéticos, servem para refletir sobre os impactos potenciais da expansão urbana e sua capacidade de manter a qualidade de vida da população e do ambiente natural em um cenário de aumento de $3 / 4$ no número de domicílios.

Especificamente em relação à região do Isidoro, deve-se reforçar que essa é a porção do município com maior probabilidade de concretização das simulações, pois, diferentemente do restante do município, existe um plano de habitação em execução que prevê 54.340 moradias no cenário 1 e 67.623 no cenário 2 (BELO HORIZONTE, 2011b).

0 crescimento domiciliar ocorrido na última década nas categorias de zoneamento Zeis-1 e Zeis-3 mostra que, apesar do arrefecimento da TCG ao longo das últimas décadas, esses ainda são lugares dinâmicos, que possuem potencial de adensamento e que certamente terão esses potenciais explorados, uma vez que se trata da categoria de zoneamento menos vulnerável à legislação urbanística do município. Os resultados mostram que em 2011 existiam 101.723 domicílios nesses locais, que ainda podem ser adensados em cerca de $20 \%$, chegando a comportar 18.439 novas moradias precárias, distribuídas de forma homogênea em todas as partes da capital. Assim como no restante do município, as áreas de Zeis também apresentam escassez de terrenos vazios e possuirão a maioria do seu adensamento domiciliar se manifestando a partir de novas construções surgidas nos fundos de quintal, ou nas verticalizações de até três pavimentos erigidas acima das lajes dos domicílios precários, nas construções conhecidas como "puxadinhos".

\section{Conclusão}

A partir de uma perspectiva metodológica que reforça a interação entre SIG e a técnica de mapeamento dasimétrico, analisou-se na escala intraurbana de quadras (com o município de Belo Horizonte) um modelo capaz de projetar cenários de aumento e distribuição da oferta domiciliar (adensamento domiciliar máximo), inclusive no que tange aos seus potenciais impactos sobre a verticalização da mancha urbana. A importância dessa análise

\footnotetext{
$\overline{8}$ Incluindo o cenário de adensamento domiciliar previsto na região do Isidoro.
} 
é predicada na necessidade de criar instrumentos eficientes de planejamento em pequenas escalas, que corrijam desequilíbrios da expansão domiciliar e do alto grau de antropização presente na capital mineira. Espera-se, assim, que este artigo contribua para a difusão das novas potencialidades advindas do geoprocessamento na demografia e nas áreas relativas ao planejamento urbano e regional.

A comparação dos resultados da simulação permite qualificar a legislação atual como bastante permissiva (apesar de as últimas alterações adotarem maiores instrumentos de restrição). Embora esse seja um limite máximo de ocupação domiciliar, fica claro que existem mecanismos na legislação municipal atual que possibilitam a saturação de novos espaços urbanos, que podem se tornar vilas e aglomerados ainda mais densos ou bairros de classe média com saturação de infraestrutura urbana. Acredita-se, ainda, que uma avaliação dos resultados em escalas mais refinadas (intraurbanos), possíveis a partir da metodologia desenvolvida nesse artigo, permita identificar locais que podem vir a se concretizar (ou estão se concretizando) como focos de adensamento maiores do que seria desejável. Poder-se-ia, dessa forma, antever e evitar problemas decorrentes do adensamento urbano, como os engarrafamentos e problemas de abastecimento de água por rede subdimensionada que têm ocorrido, por exemplo, nos bairros Buritis, Estoril, Castelo e Novo Engenho Nogueira, criados na última década sem uma infraestrutura urbana adequada à sua densidade.

Os problemas decorrentes do adensamento exagerado, como verificado nos bairros supracitados, estimulam uma discussão para o planejamento urbanístico futuro da capital. Em particular, recomenda-se o aumento dos valores da QT na legislação vigente para níveis maiores do que os atuais e preferencialmente acima dos praticados pelo mercado, visando a minimização do adensamento domiciliar e problemas decorrentes nas quadras que ainda apresentam alto potencial construtivo.

Já o cenário 2 permite uma reflexão suplementar à do parágrafo anterior, pois, à medida que os lotes vagos vão diminuindo, aumenta a tendência de o mercado imobiliário se apossar de edificações passíveis de demolição. A renovação urbana é um nicho de mercado cuja atividade no município está se expandindo rapidamente, principalmente nos espaços mais nobres da capital, como mostram os dados de evolução do cadastro do IPTU, com renovação de 191 edificações entre 2010 e 2011, contra uma média de 127 por ano entre 2006 e 2010. Estes dados ainda mostram que, embora o preço do $\mathrm{m}^{2}$ nestes locais seja mais elevado, tem havido uma constante demanda por parte dos incorporadores imobiliários, geralmente para fins de especulação. 0 aumento anual do número de demolições sinaliza a necessidade de se pensar melhor nesse tipo de mecanismo, sendo que os resultados aqui levantados ajudam a identificar os locais do município mais aptos ao processo de renovação, buscando assim um melhor planejamento do uso do solo urbano.

Ressalta-se que o uso de informações georreferenciadas oficiais do município, assim como o envolvimento de vários especialistas na elaboração dos pressupostos, foi fundamental para tornar o modelo mais acurado, de tal forma que estas simulações possam ser mais úteis como instrumentos de planejamento intraurbano da capital, provando, inclu- 
sive, que a Lei n. 9.959/10, apesar de ser considerada a mais restritiva já implantada no planejamento da capital, ainda mostra-se bastante permissiva.

É nesse sentido que a metodologia desenvolvida pode servir para o aprimoramento de diversas atividades de manutenção e planejamento do meio urbano, tais como a planificação de políticas de infraestrutura e habitação, a expansão e manutenção de redes de serviços públicos ou privados (água, eletricidade, esgotamento sanitário, telefonia, entre outros), a identificação de locais para a instalação de equipamentos públicos, a caracterização de novas áreas de assentamentos precários e a identificação da vulnerabilidade ambiental presente e futura da população. Todos esses elementos mostram a importância da desagregação espacial da informação urbana em pequenas áreas (TORRES, 2006).

Comparando de forma sintética a densidade domiciliar atual com a projetada conforme os parâmetros da referida Lei, percebe-se que, sob a ótica de um cenário conservador, embora aparentemente próxima à saturação dos espaços de expansão urbana, a capital ainda possui instrumentos legais que permitem e estimulam um expressivo adensamento domiciliar. Este adensamento está ocorrendo de forma contínua a partir da ocupação em lotes vagos e, em um segundo momento, se acentuará por meio da renovação urbana. Como o processo está ocorrendo em todas as porções do município, os resultados apontam a necessidade de os gestores urbanos desenharem estratégias de intervenção distintas para cada espaço da capital, sendo que os dados da simulação indicam para cada quadra do município o impacto que poderá ser resultante dos cenários projetados, possibilitando uma intervenção mais adequada para cada tipo de situação.

Embora o foco deste artigo seja eminentemente metodológico, os resultados mostram a possibilidade de utilização de instrumentos que viabilizem a criação de cenários que alimentem um debate sobre a morfologia urbana, mormente em torno da discussão sobre a compactação ou espraiamento da urbanização brasileira e suas repercussões (e demandas) para o planejamento e as políticas públicas. Nesse sentido, deve-se frisar que estudos complementares voltados para o planejamento da paisagem e da qualidade ambiental urbana podem ser feitos utilizando-se cenários de expansão domiciliar, ao demonstrar para onde e quanto a cidade pode crescer. Essa questão é particularmente relevante tendo em vista o aparente paradoxo entre o avanço da transição demográfica brasileira, com a redução da taxa de crescimento e, em algumas décadas, do tamanho da população urbana brasileira, e uma taxa relativamente maior de crescimento na formação de domicílios em função de novos arranjos domiciliares e de família e da dinâmica do mercado imobiliário urbano. Além disso, uma análise mais aprofundada dos dados permitirá verificar as implicações positivas e negativas que o crescimento e adensamento domiciliar causarão em Belo Horizonte, principalmente por meio da verticalização e adensamento domiciliar. Uma hipótese a ser investigada, apresentada por Martine (2007) e Bremner et al. (2010), é sobre a existência de razões demográficas, socioeconômicas e ambientais que fariam os grandes centros urbanos adensados potencialmente mais sustentáveis a médio e longo prazos, por gerarem economias de escala que possibilitem a oferta mais 
eficiente de serviços e infraestrutura, desde que políticas de manutenção da infraestrutura urbana voltadas para o adensamento sejam adotadas (MARTINE, 2007; BREMNER et al., 2010). Um planejamento ordenado da ocupação urbana pode potencializar benefícios de um maior adensamento populacional, ao gerar economias de escala que possibilitam a oferta mais eficiente de serviços e infraestrutura.

0 método proposto neste artigo possui algumas limitações. Em primeiro lugar, deve-se ressaltar que a qualidade dos insumos básicos fornecidos pela Prefeitura de Belo Horizonte é a principal responsável pela viabilidade do produto final e seu constante aprimoramento contribui para uma simulação cada vez mais precisa. Outra limitação é a alta dependência dos pressupostos com o PDM e a LPOUS. Caso esses instrumentos tenham parâmetros urbanísticos alterados, a metodologia e os resultados dos cenários devem ser revistos.

Por fim, verifica-se que a demografia vive um momento oportuno para uma maior absorção das geotecnologias, em função das novas fontes de dados que se tornam acessíveis, das inovações nos recursos computacionais voltados para simulações e da maior abertura da demografia (assim como outras disciplinas) a diálogos interdisciplinares. Esse conjunto de possibilidades favorece, em particular, o avanço da compreensão da dinâmica demográfica em pequenas áreas, particularmente no espaço intraurbano. Assim, espera-se que a integração de dados demográficos às geotecnologias seja mais difundida entre os demógrafos, e que o exercício metodológico aqui proposto sirva como exemplo de possibilidades de análise de informações contemporâneas e de simulação de cenários futuros em pequenas áreas.

\section{Referências}

BELO HORIZONTE. Prefeitura Municipal. Lei n. 9.959/10, de 20 de julho de 2010. Altera as leis n. 7.165/96 - que institui o Plano Diretor do Município de Belo Horizonte - e n. 7.166/96 - que estabelece normas e condições para parcelamento, ocupação e uso do solo urbano no Município, e dá outras providências. Diário Oficial do Município de Belo Horizonte. Belo Horizonte, 2010.

. Prefeitura Municipal. Base georreferenciada de quadra-face do Imposto Territorial e Predial Urbano (IPTU), referente a setembro de 2011. Belo Horizonte, 2011a (circulação restrita).

. Prefeitura Municipal. Plano Urbano Ambiental da Região do Isidoro. Belo Horizonte: Secretaria Municipal de Políticas Urbanas, 2011b (circulação restrita).

. Prefeitura Municipal. Bases georreferenciadas de Regionais de Planejamento, quadras e lotes do Cadastro Técnico Municipal (CTM), referentes a setembro de 2011. Belo Horizonte, 2011c (circulação restrita).

Prefeitura Municipal. Base georreferenciada do Zoneamento Municipal, referente a setembro de 2011. Belo Horizonte, 2011d (circulação restrita).

BRASIL. Lei n. 6.766, de 19 de dezembro de 1979. Dispõe sobre o parcelamento do solo urbano e dá outras providências. Diário Oficial da União, Brasília, 1979.

Senado Federal. Estatuto da Cidade - Guia para implementação pelos municípios e cidadãos: Lei n. 10.257, de 10 de julho de 2001. Estabelece diretrizes gerais da política urbana. Brasília, 2005. 
BREMNER, J.; FROST, A.; HAUB, C.; MATHER, M.; RINGHEIM, K.; ZUEHLKE, E. World population highlights: key findings for PRB's 2010 world population data sheet. Population Bulletin PRB, v. 65, n. 2, 2010. Disponivel em: 〈http://www.prb.org/pdf10/65.2highlights.pdf〉. Acesso em: $01 \mathrm{fev} .2012$.

CAVALCANTI, C. (Org.). Meio ambiente, desenvolvimento sustentável e políticas públicas. 2. ed. São Paulo: Cortez, 1999.

COTA, D. Legislação urbana e capital imobiliário na produção de moradias, em Belo Horizonte: um estudo de caso. 2002. 123f. Dissertação (Mestrado em Geografia) - Instituto de Geociências, Universidade Federal de Minas Gerais, Belo Horizonte, 2006.

. A parceria público-privada na política urbana brasileira recente: reflexões a partir da análise das operações urbanas em Belo Horizonte. 2010. 430f. Tese (Doutorado em Geografia) - Instituto de Geociências, Universidade Federal de Minas Gerais, Belo Horizonte, 2010.

EICHER, C.; BREWER, C. Dasymetric mapping and areal interpolation: implementation and evaluation. Cartography and Geographic Information Science, v. 28, n. 2, p. 125-138, 2001.

EPAMINONDAS, L. A legislação urbanística e a produção do espaço: estudo do bairro Buritis em Belo Horizonte. 2006. 211f. Dissertação (Mestrado em Geografia) - Instituto de Geociências, Universidade Federal de Minas Gerais, Belo Horizonte, 2006.

FERREIRA, T. Planejamento urbano: reflexões sobre as práticas no município de Belo Horizonte. 142f. Dissertação (Mestrado em Geografia) - Instituto de Geociências, Universidade Federal de Minas Gerais, Belo Horizonte, 1999.

IBGE. Censo Demográfico 2000: agregado por setores censitários dos resultados do universo. Rio de Janeiro: IBGE, 2002.

Censo Demográfico 2010: agregado por setores censitários dos resultados do universo. Rio de Janeiro: IBGE, 2011.

JANNUZZI, P. Cenários futuros e projeções populacionais para pequenas áreas: método e aplicação para distritos paulistanos 2000-2010. Revista Brasileira de Estudos de População, v. 24, n. 1, p. 109-136, 2007.

LEMOS, M. et al. (Orgs.). Belo Horizonte no século XXI. Belo Horizonte: Cedeplar/UFMG, 2004. Disponivel em: 〈http://www.cedeplar.ufmg.br/pesquisas/projetos-concluidos/ projeto-bhseculo-xxi.php〉. Acesso em: 27 ago. 2011.

MARTINE, G. O lugar do espaço na equação população/meio ambiente. Revista Brasileira de Estudos de População, v. 24, n. 2, p. 181-190, 2007.

MATOS, R. Evolução urbana e formação econômica de Belo Horizonte. Belo Horizonte: Cedeplar/ UFMG, 1992 (Texto para discussão, 64).

MENNIS, J.; HULTGREN, T. Intelligent dasymetric mapping and its application to areal interpolation. Cartography and Geographic Information Science, v. 33, n. 3, p. 179-194, 2006.

PDDI - Plano Diretor de Desenvolvimento Integrado da Região Metropolitana de Belo Horizonte. Relatório final de definição das propostas de políticas setoriais, projetos e investimentos prioritários. Belo Horizonte: Cedeplar/UFMG, 2011. Disponível em: 〈www.rmbh.org.br〉. Acesso em: 01 jul. 2011.

REIBEL, M.; AGRAWAL, A. Areal interpolation of population counts using pre-classified land cover data. Springer Science, v. 36, n. 5-6, p. 619-633, 2007.

REZENDE, D.; ULTRAMARI, C. Plano diretor e planejamento estratégico municipal: introdução teóricoconceitual. Revista de Administração Púlica On Line, v. 41, n. 2, p. 255-271, 2007. Disponível em: 〈http://dx.doi.org/10.1590/S0034-76122007000200005〉. Acesso em: 27 maio 2011. 
SANTOS, R. Projeções populacionais para pequenas áreas a partir de cenários econômicos: aplicação de ratio methods para a região do Alto Paraopeba-MG, 2010-2025. 2010. 98f. Dissertação (Mestrado em Demografia) - Cedeplar, Universidade Federal de Minas Gerais, Belo Horizonte, 2010.

TORRES, H. Demografia urbana e políticas sociais. Revista Brasileira de Estudos de População, v. 23, n. 1, p. 27-42, 2006.

UMBELINO, G. Proposta metodológica para avaliação da população residente em áreas de risco ambiental: o caso da bacia hidrográfica do Córrego do Onça/MG. 2006. 141f. Dissertação (Mestrado em Demografia) - Cedeplar, Universidade Federal de Minas Gerais, Belo Horizonte, 2007.

Simulações de distribuição espacial domiciliar e projeções demográficas intraurbanas com apoio de geotecnologias. 2012. 193f. Tese (Doutorado em Demografia) Cedeplar, Universidade Federal de Minas Gerais, Belo Horizonte, 2012.

UNFPA. Relatório sobre a situação da população mundial 2011: pessoas e possibilidades em um mundo de 7 bilhões. Brasília, 2011.

\title{
Sobre os autores
}

Glauco Umbelino é doutor em Demografia, professor da Faculdade Interdisciplinar em Humanidades - FIH e pesquisador do Núcleo de Geociências - NuGeo, Universidade Federal dos Vales do Jequitinhonha e Mucuri - UFVJM.

Clodoveu Davis Jr. é doutor em Ciência da Computação, professor e pesquisador do Departamento de Ciência da Computação, Universidade Federal de Minas Gerais - UFMG.

\section{Endereço para correspondência}

\author{
Glauco Umbelino \\ A/C Correios, Caixa Postal 08, Bairro Centro \\ 39100-970 - Diamantina-MG, Brasil \\ Clodoveu Davis Jr. \\ Universidade Federal de Minas Gerais \\ Av. Pres. Antônio Carlos, 6627, prédio do ICEx, sala 4012 \\ 31270-010 - Belo Horizonte-MG, Brasil
}

\section{Abstract}

Simulation of the maximum number of households allowed by block in Belo Horizonte

This paper proposes a methodology to simulate scenarios of maximum number of households for each city block in the municipality of Belo Horizonte. The parameters used in the simulation were obtained from municipal registration data as well as from the 2000 and 2010 Census results. The simulation is based on geo-referenced data for each municipal block combined with dasymetric mapping of the capital city's housing distribution in 2011. The study simulates the greatest amount of additional housing that would occur, under the limits of municipal law, if all vacant urban lots were occupied to their maximum capacity, and if buildings now at risk of demolition were substituted by new buildings constructed so as to yield their highest household capacity. 
The results show the maximum number of households that Belo Horizonte would have if these conditions were achieved. In addition to demonstrating the maximum number of households allowed in each city block, the paper identifies where urban expansion and consolidation is likely to occur. This exercise also provides a contribution to the field of small area population projections. The proposed scenarios additionally help to guide discussions about priority areas and potential alternatives for urban expansion and consolidation, as well as on their implications for urban planning.

Keywords: Household simulation. Geotechnologies. Dasymetric mapping. Urban sprawl.

\section{Resumen}

\section{Simulación de la cantidad máxima de viviendas permitidas por cuadra en Belo Horizonte}

El artículo propone una metodología de simulación de la cantidad máxima de viviendas que podría tener cada cuadra en el municipio de Belo Horizonte. Los parámetros utilizados en la simulación se extrajeron de la información del registro de la Municipalidad, asociada con los resultados de los censos de 2000 y 2010. La simulación se desarrolló a partir de una base de datos georreferenciada de las cuadras del municipio, construida mediante un mapeo dasimétrico de la distribución de las viviendas en la ciudad en 2011. En una segunda etapa se realizó la simulación del límite máximo de nuevas viviendas permitidas por las leyes municipales, en el caso que todos los lotes baldíos fueran ocupados a su máxima capacidad y que todas las edificaciones con potencial de demolición dieran lugar a nuevos edificios residenciales construidos también a su capacidad habitacional máxima. Los resultados muestran cuál sería el máximo de viviendas que podrían llegar a instalarse en Belo Horizonte en el futuro. Esta información sirve como insumo para las proyecciones demográficas de pequeñas áreas, pues muestra hacia dónde se puede producir la expansión y densificación de viviendas, además del límite máximo de viviendas soportado en cada cuadra. De forma complementaria, se sugieren caminos para discutir los límites potenciales de la ocupación urbana de Belo Horizonte, las zonas preferenciales de aglomeración y sus implicaciones para la planificación.

Palabras clave: Simulación domiciliar. Geotecnologías. Mapeo dasimétrico. Expansión urbana. 
